\title{
NUMERICAL INVESTIGATION OF THERMAL AND MECHANICAL DEVIATIONS IN A HOT FORGING PROCESS OF 16MnCr5 AND 42CrMo4 STEEL
}

\author{
${ }^{1}$ Bernd-Arno BEHRENS, ${ }^{2}$ Wolfram VOLK, ${ }^{1}$ Alexander CHUGREEV, ${ }^{1}$ Michael TILL, ${ }^{2}$ Daniel MAIER, \\ ${ }^{1}$ Christoph BÜDENBENDER
}

\author{
${ }^{1}$ Leibniz Universität Hannover, Institute of Forming Technology and Machines, Garbsen, Germany, EU, \\ buedenbender@ifum.uni-hannover.de \\ ${ }^{2}$ Technical University of Munich, Chair of Metal Forming and Casting, Garching, Germany, EU
}

https://doi.org/10.37904/metal.2019.693

\begin{abstract}
The development of tools in bulk metal forming for the production of steel components consists of an iterative development process and requires a large number of test tools, resulting in high costs as well as increased production time. The simulation of process steps on the basis of the finite element method is an established technique for tool design and provides a significant contribution to the optimization of processes in the development phase. Thermally and mechanically induced deviations from the desired component geometry occur due the forging process. The approximation of the actual to the target geometry of the component must be worked out in several iteration loops by adapting the process conditions, or by modifying the forming tools. A newly developed process-accompanying compensation strategy helps to reduce the deviations by modifying the forming tool and process conditions within the virtual product development phase. In that regard, the numerical investigation of a forging process has been carried out in this study. The influence of different process conditions and their influence on the workpiece deviation are investigated. For this purpose, first of all the material data such as flow curves and coefficients of thermal expansion are determined in experimental tests. The coefficients for an analytical flow curve approach called GMT, which is implemented in the commercial software simufact.forming are computed for the investigated steel grades $16 \mathrm{MnCr} 5$ and $42 \mathrm{CrMo} 4$. Finally, the flow curve approach was validated by comparing numerical and experimental results of a uniaxial compression test. Also the numerical results of the forging process with different initial forging temperatures are compared with each other and the deviations of the workpiece are discussed.
\end{abstract}

Keywords: Bulk metal forming, GMT material model, FEM

\section{INTRODUCTION}

Die forging enables component accuracy to DIN ISO 286 IT 14-16, while precision forging permits tolerances in the IT 8-9 range [1]. Apart from the friction conditions and elastic tool deformations, the stress condition and the prevailing temperature distribution in the tool and workpiece are responsible for the component deviations [2]. The retraction of the punch leads to a partial relief of residual stresses in the workpiece and therefore elastic deformations after the forming process. Furthermore, the change of the stress state leads to a contraction of the die shape, which results in a further plastic deformation of the workpiece [3]. Moreover, workpiece shrinkage due to dissipated thermal energy and the heat treatment of the workpiece after the process lead to decisive factors for the dimensional deviations of massively deformed components [4]. The compensation of these dimensional deviations is made possible by a computer-aided modification of the forming tools in order to increase the accuracy of the forged parts. The commercial simulation programs for forging processes (e.g. Forge, Simufact.forming) allow the thermos-mechanically coupled simulation of the entire forging process chain. An approach for the calculation of correction for the tool geometry is presented in [5]. These corrections are computed on the basis of the node information from the numerical calculation in order to compensate the deformations of the tool in the forming process. With the result and the use of a correction algorithm, the elastic deformations on the forming surfaces are already taken into account during 
the design phase. In addition, a sensitivity analysis is performed to determine the influence of individual parameters on the overall deformation [6]. In [7] the computer-aided design of engravings for the precision forging of gears is carried out.

The objective of the project presented here is the development of a process-accompanying compensation strategy for the reduction of dimensional deviations in massively formed components. Thereby, thermally and mechanically factors are taken into account. In this paper the results of the material characterisation and the numerical forming simulation are presented. By this means, the distortion of hot forging component depending on different process conditions can by analysed.

\section{MATERIAL CHARACTERISATION}

\subsection{Material characterisation - Flow behaviour}

Uniaxial compression tests were carried out to determine flow curves for the grades $16 \mathrm{MnCr} 5$ (DIN 1.7131) and 42CrMo4 (DIN 1.7225) by means of servo-hydraulic forming simulation Gleeble 3800-GTC. The used cylindrical specimens had a diameter of $11 \mathrm{~mm}$ and a height of $18 \mathrm{~mm}$. The tests were carried at four different temperatures $\left(900{ }^{\circ} \mathrm{C}, 1000{ }^{\circ} \mathrm{C}, 1100{ }^{\circ} \mathrm{C}\right.$ and $\left.1200{ }^{\circ} \mathrm{C}\right)$ and three different strain rates $\left(1 \mathrm{~s}^{-1}, 10 \mathrm{~s}^{-1}, 50 \mathrm{~s}^{-1}\right)$. The specimens were conductively heated. Graphite were used as lubricant. The samples were upset to a strain of $\varphi=0.7$. Up to this point, the influence of friction on the measurement result is negligibly small [8]. The resulting data from the testing machine were used to compute the coefficients for the analytical flow curve approach called GMT, which is depicted in the following equation (1):

$\sigma_{F}=C_{1} \cdot e^{C_{2} \cdot T} \cdot \varphi^{n_{1} \cdot T+n_{2}} \cdot e^{\frac{I_{1} \cdot T+I_{2}}{\varphi}} \cdot \dot{\varphi}^{m_{1} \cdot T+m_{2}}$

For computing the coefficients $C_{1}, C_{2}, n_{1}, n_{2}, I_{1}, I_{2}, m_{1}$ and $m_{2}$ the GRG-nonlinear optimization algorithm was used. The resulting stress-strain curves for different testing temperatures at strain rate $1 \mathrm{~s}^{-1}$ are shown in Figure 1. With the increase of temperature, the level of flow stress decreases as expected. Both steel alloys showed this behaviour.
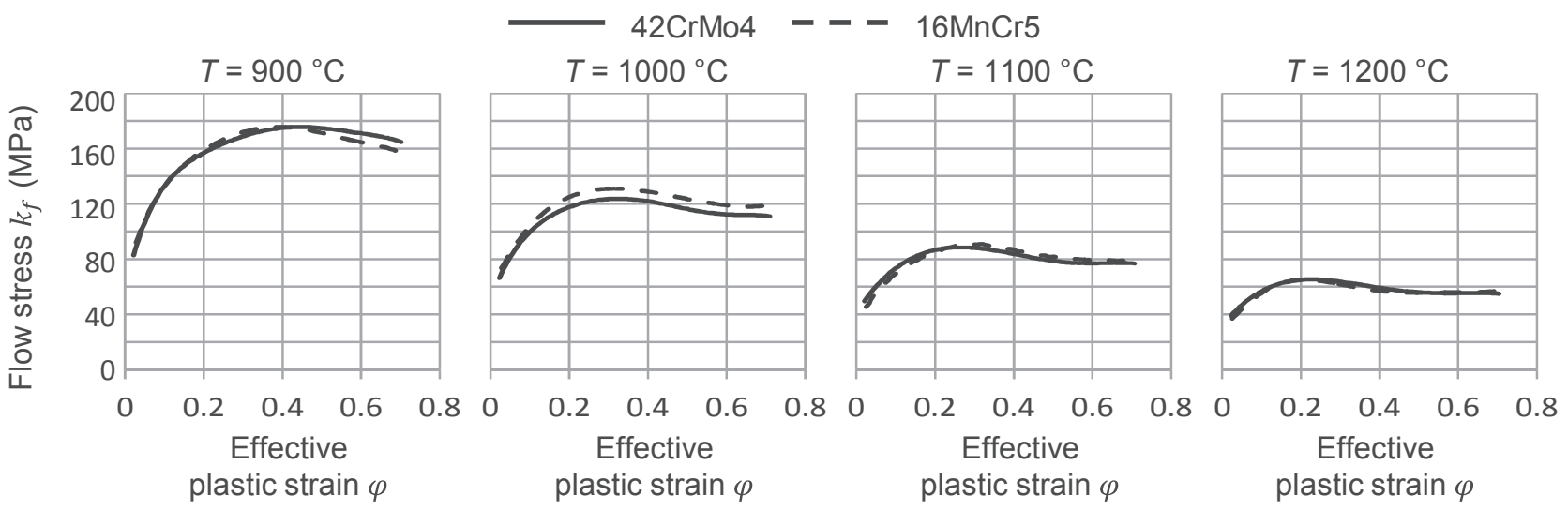

Figure 1 Stress-strain curves for $42 \mathrm{CrMo} 4$ and $16 \mathrm{MnCr} 5$ at different temperatures and at strain rate $1 \mathrm{~s}^{-1}$

In Figure 2 the resulting stress-strain curves at the test temperatures $1200{ }^{\circ} \mathrm{C}$ and at the strain rate $1 \mathrm{~s}^{-1}$, $10 \mathrm{~s}^{-1}$ and $50 \mathrm{~s}^{-1}$ for the two investigated steel alloys are depicted. With the increase of the strain rate the level of the flow stress increases at lower strains, then subsequently the level of stress decreases. This behaviour is based on thermally activated recovery and recrystallization processes in the material at higher temperatures [9]. The dependence of the strain rate is depicted exemplary in Figure 2 (left) for $1200^{\circ} \mathrm{C}$. 

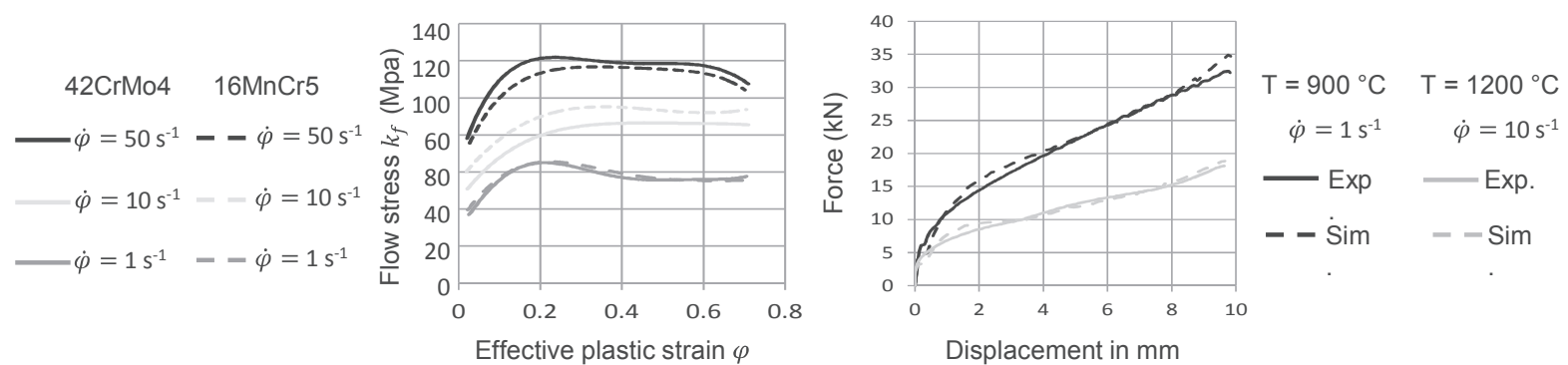

Figure 2 Stress-strain curves at $1200{ }^{\circ} \mathrm{C}$ for different strain rates (left); Force-displacement curve of the uniaxial compression test (right)

To validate the coefficients of the GMT flow curve approach, a numerical model of the uniaxial compression test was built and the compression test was simulated. The flow curve was modelled with the GMT approach, which has been parameterized with the coefficients that were determined in the material characterisation. The resulting force-displacement curve from simulation and experimental tests are compared in Figure 2 (right) are in a good agreement. The computed coefficients are presented in Table 1.

Table 1 Coefficients for the GMT flow curve approach for the steel alloys $16 \mathrm{MnCr} 5$ and $42 \mathrm{CrMo} 4$

\begin{tabular}{cccccccccc} 
& $C_{1}$ & $C_{2}$ & $n_{1}$ & $n_{2}$ & $I_{1}$ & $I_{2}$ & $m_{1}$ & $m_{2}$ & $\varphi_{\min }$ \\
\hline 16MnCr5 & 5382.739 & -0.00377 & -0.00039 & 0.33327 & $-1.5 \mathrm{E}-05$ & -0.01418 & 0.000134 & 0.000563 & 0.02 \\
\hline 42CrMo4 & 5988.386 & -0.00389 & -0.00038 & 0.350793 & $-7.2 \mathrm{E}-06$ & -0.015 & 0.00015 & 0.000563 & 0.02 \\
\hline
\end{tabular}

\subsection{Material characterisation - Thermal expansion coefficient}

To determine the coefficients of thermal expansion, a dilatometer of the manufacturer TA Instruments was used. The coefficients of thermal expansion were investigated in the range from $20^{\circ} \mathrm{C}$ to $1200^{\circ} \mathrm{C}$. In this study the workpiece materials $16 \mathrm{MnCr} 5$ (DIN 1.7131) and 42CrMo4 (DIN 1.7225), and also the used tool materials 32CrMoV12-28 (DIN 1.2365) and 55NiCrV7 (DIN 1.2714), were examined. The coefficient of thermal expansion was computed with help of equation (2) by means of the dilatometer tests:

$$
\alpha=\frac{\Delta L}{L_{0} \cdot \Delta T}
$$

$$
\Delta L \text { length change } \quad L_{0} \text { output length } \quad \Delta T \text { temperature change }
$$

In Figure 3 the results of the coefficients of thermal expansion (CTE) are presented. In Figure 3 (left) shows the results of workpiece steel grades, $16 \mathrm{MnCr} 5$ und $42 \mathrm{CrMo} 4$, and in Figure 3 (right) the tool steel grades, 55NiCrV7 and 32CrMov12-28 are presented.
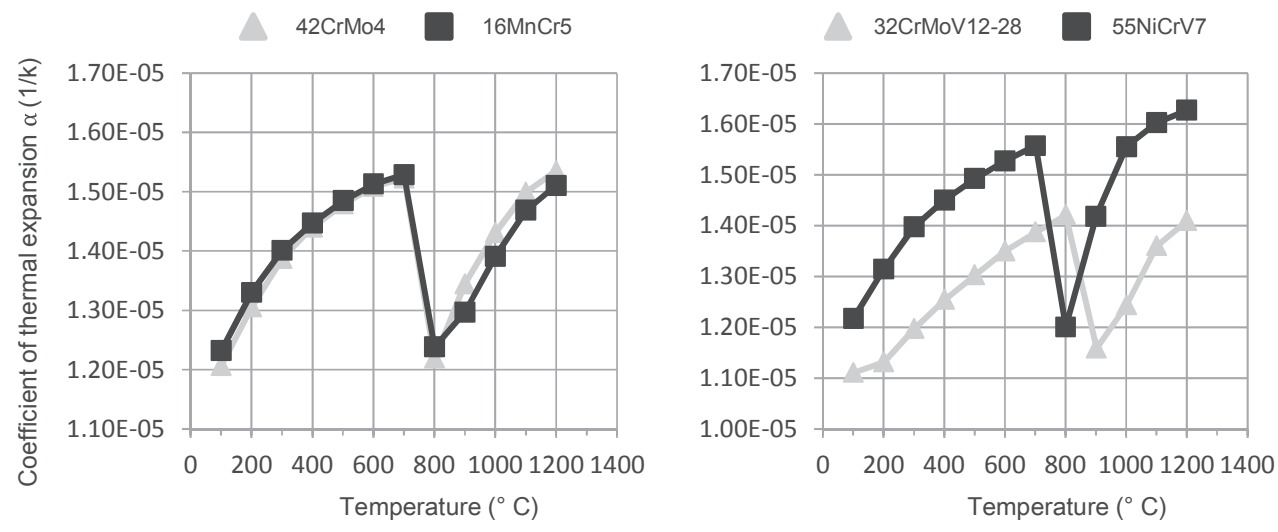

Figure 3 CTE for the workpiece materials (left); CTE for the tool materials (right) 
With increasing temperature up to $700{ }^{\circ} \mathrm{C}$ the CTE is also increasing. Subsequently the CTE decreases at $800{ }^{\circ} \mathrm{C}$ and further increases at higher temperatures can be observed. All four investigated steel grades showed this behaviour. The decrease and increase of the CTE between $700{ }^{\circ} \mathrm{C}$ and $900{ }^{\circ} \mathrm{C}$ is caused by crystalline transformation of the metal. This causes a change in volume which is reflected in the measured change in length and influences the CTE value [10]. After this point the CTE increases again.

\section{FORGING PROCESS AND NUMERICAL MODEL}

In this approach a forged part, which is highly susceptible to distortion due to its geometric properties, was investigated. The hot forging process is divided into three steps. In the first step the billet is heated up. In the second step the billet is formed and in the third step the billet is quenched to room temperature. The CAD representation of the investigated forming tool is presented in Figure $4 \mathbf{a}$. The rotationally symmetric forging part is shown in Figure $\mathbf{4} \mathbf{b}$. A numerical model was built using the commercial software simufact.forming, which is shown Figure $4 \mathrm{c}$. The numerical investigation was subdivided into three steps, so that the heating process, the forming process and quenching could be considered individually. The investigated process is a rotation symmetric forming process consisting of the upper and lower die and the workpiece. The upper and lower dies are modelled as an elastic body. The GMT flow curve approach was used to calculate the material behaviour of the workpiece. Friction is described by using the combined friction model which includes the coulomb's model with a friction coefficient of $\mu=0.3$ and the tresca model with a friction coefficient of $m=0.08$ for the contact between tools and workpiece. These values were taken from literature [11]. The data for the GMT flow curve approach and for the friction model were taken from the material characterisation. To investigate the distortion of the formed component, the sectional view of the component after cooling in the air was considered. The heat transfer coefficient from metal to air was taken from simufact.forming database. Four initial forming temperatures were investigated $\left(900^{\circ} \mathrm{C}, 1000^{\circ} \mathrm{C}, 1100^{\circ} \mathrm{C}, 1200^{\circ} \mathrm{C}\right)$ and the radius of the forging part was measured after cooling in air.

(a)

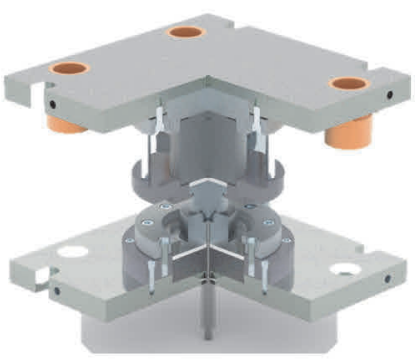

(b)

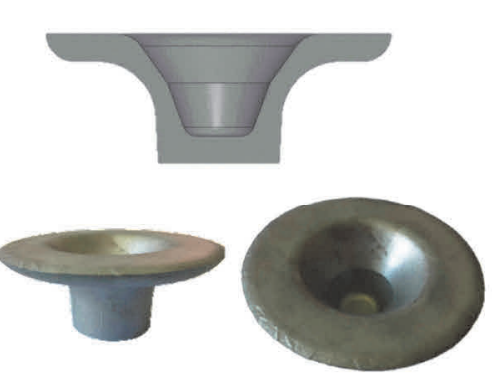

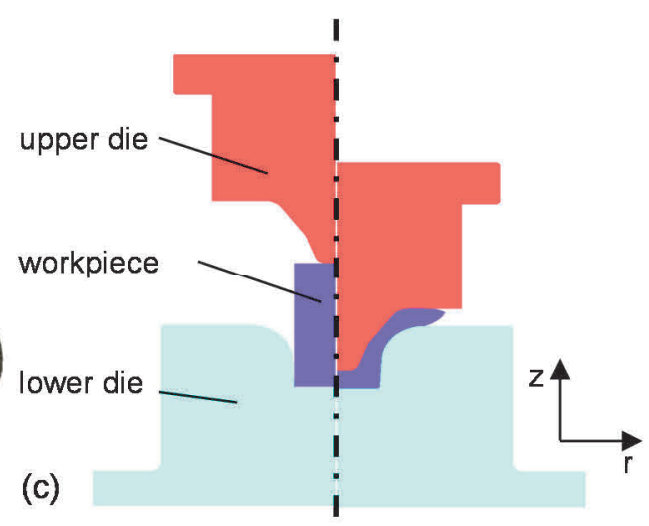

Figure 4 CAD representation of the forming tool (a); CAD sectional view representation and experimental Result of experimental tests (b); Numerical model of the investigated forging process (c)

\section{NUMERICAL RESULTS}

In Figure 5 the results of the forming simulation are presented. The temperature distribution and the effective plastic strain in the formed component are illustrated. In this presented result of the numerical simulation the initial temperature of the billet was $1200{ }^{\circ} \mathrm{C}$. Through the dissipation of plastic work in heat, the temperature of the billet increased up to $1254^{\circ} \mathrm{C}$ during the process. The maximum of computed effective plastic strain was 4.87 . 


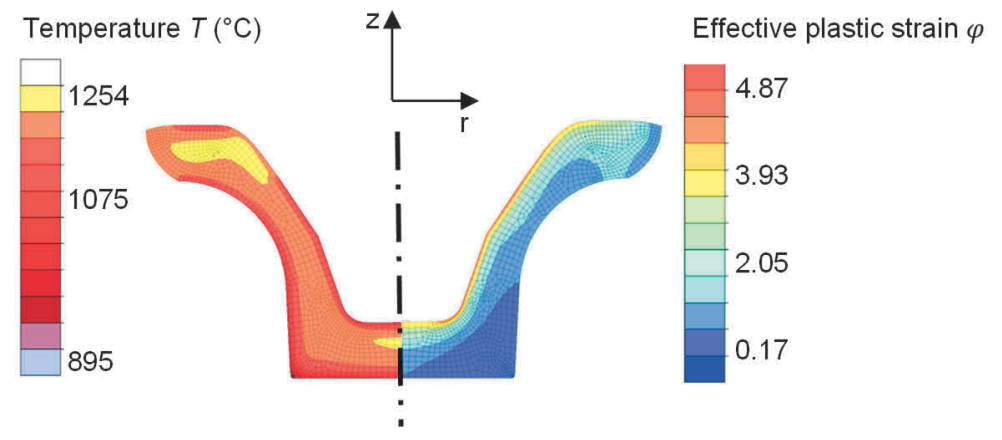

Figure 5 Temperature distribution (left); Effective plastic strain of the formed component (right)

In Figure 6 the results of the sectional view of the formed component after cooling in air for two steel grades, which are generated with help of the numerical model, are presented. $R_{1}$ and $R_{2}$ represent the radii of the component, respectively. Both types of steel show different radii at each initial forging temperature. With the increase in the investigated forging temperatures, the required forming force is reduced. This is caused by the decrease in yield stress as the temperature rises, as described in the section concerning material characterisation of the two steel grades that were used. The lower forming force also reduces the elastic deformation of the dies. Furthermore, the heat transfer coefficients, which has a decisive influence on the heat transfer between the workpiece and the tool is in turn dependent on the contact pressure [12]. The contact pressure in turn depends on the current forming force. Different heat transfer conditions result in a inhomogeneous temperature field in the forged part. Due to the cooling in the air, differentiated thermal stresses occur. All these mentioned factors are influencing the shown variation of the radii of the presented forging part (Figure 6). Whereas friction as an influencing factor can be excluded in this investigation, since the coefficient of friction is assumed as constant at any place and time and was not selected as temperaturedependent. On basis of the numerical results it can be concluded that the predominand influencing factor on the deviations of the forging part is the initial forging temperature, which in turn influnces the mentioned process condition, which in turn influnces the deviations, too.
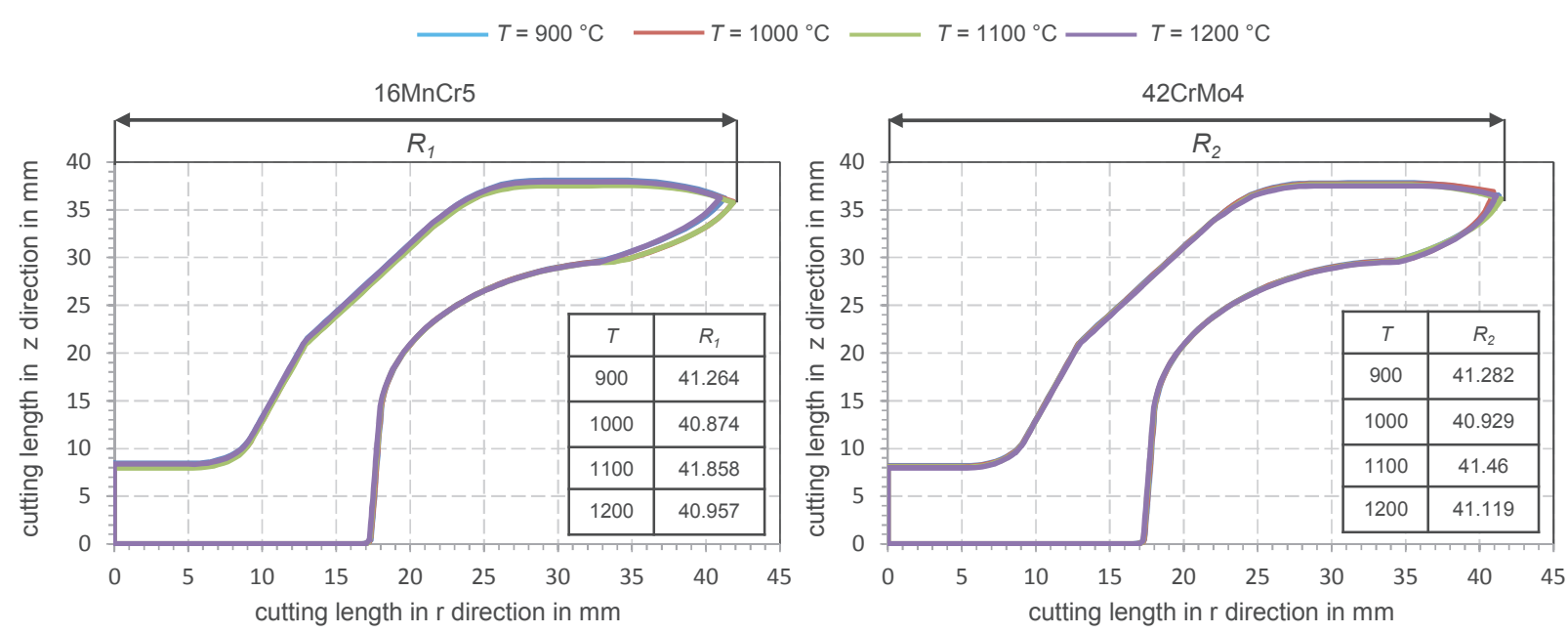

Figure 6 Sectional view of the formed component with different initial forging temperature after cooling in air. On the left hand side the results for $16 \mathrm{MnCr} 5$ and on the right hand side the results for $42 \mathrm{CrMo} 4$

\section{CONCLUSION AND OUTLOOK}

Within this study the thermal and mechanical deviations were investigated in a hot forging process. Herefore, a well-founded material characterisation of the materials $16 \mathrm{MnCr} 5$ (DIN 1.7131) and 42CrMo4 (DIN 1.7225) 
was carried out in order to determine the flow behaviour at process related temperature and strains rates. Moreover, the coefficients of thermal expansion of the workpiece steel and of the tool steels were investigated. A numerical model was created to virtually represent the heating process of the billet, the forging process and the quenching of the billet to room temperature by incorporating the data of the material characterisation. With help of the numerical model the extent of the distortion in relation to different forging temperatures was investigated depending on different forging temperatures. The results showed that the distortion depends on the initial forging temperature. In future work, the findings of this paper will be used to determine significant points to observe the distortion of components. Also the experimental results will be compared with the numerical results to validate the presented numerical model. Furthermore, the results of the numerical model will be used to develop a process-accompanying deviation compensation approach method in order to reduce the detected distortion.

\section{ACKNOWLEDGEMENTS}

The presented results are based on the framework of the research project "Development of a geometry based method for the compensation of process-related dimensional deviations of solid formed parts" under the grant number 334525444 (BE 1691/207-1). The authors would like to thank the German Research Foundation (DFG) for the financial support.

\section{REFERENCES}

[1] Industrieverband Massivumformung e.V.: Massivumformung kurz und bündig, 2013. Available from: https://www.massivumformung.de/fileadmin/user upload/8 Karriere/IMU Fachbuch 2013.pdf

[2] BALENDRA, R. Net-shape forming: state-of-the-art. Journal of Materials Processing Technology. 2001. vol. 115, pp. $172-179$.

[3] ROSOCHOWSKI, A. and BALENDRA, R. Secondary yielding of forged components due to unloading. Journal of Materials Processing Technology. 2001. vol. 115, pp. 233-239.

[4] BAUMGARTEN, J. Strategies to minimize the negative effects of elastic die deflection in closed-die Precision forming processes. Proceedings ESAFORM. 2002.

[5] AWISZUS, B. Entwicklung einer Optimierungsstrategie zur Auslegung von Umformwerkzeugen unter Berücksichtigung von Simulationsparametern. Abschlussbericht AiF-Vorhaben 13921BR. 2006.

[6] EBERT, A. Berücksichtigung der elastischen Werkzeugdeformation im Bereich der Massivumformung am Beispiel Gesenkschmieden. Dissertation. IWP, TU Chemnitz. 2009.

[7] WIARDA, M. Rechnerunterstützte Konstruktion von Gravuren für das Präzisionsschmieden von Zahnrädern. Dissertation. Gottfried Wilhelm Leibniz Universität Hannover. 1997.

[8] PÖHLANDT, K. Werkstoffprüfung für die Umformtechnik. Springer-Verlag Berlin Heidelberg GmbH. ISBN 978-3540-16722-8; ISBN 978-3-662-10908-3 (eBook) 1986.

[9] BEHRENS, B.-A., BOUGUECHA, A., HUININK, T., PESHEKHODOV, I., MATTHIAS, T., MORITZ, J. and SCHRÖDTER, J. Investigation of the flow behavior of wrought magnesium alloy AZ31 using layer compression and tensile tests. Mat.-wiss. u.Werkstofftech. 2013. vol. 44, no 9, pp. 760-767.

[10] WEIBBACH, W., DAHMS, M. and JAROSCHEK, C. Werkstoffkunde Strukturen, Eigenschaften, Prüfung. Springer Vieweg; ISBN 978-3-658-03918-9, 2015.

[11] BEHRENS, B.-A., ALASTI, M., BOUGUECHA, A., HADIFI, T., MIELKE, J. and SCHÄFER, F. Numerical and experimental investigations on the extension of friction and heat transfer models for an improved simulation of hot forging processes. International Journal of Material Forming. 2009. vol. 2, pp. 121-124.

[12] SEMIATIN, S. L., COLLINGS, E. W., WOOD, V. E. and ALTAN, T. Determination of the Interface Heat Transfer Coefficient for Non-Isothermal Bulk-Forming Processes. Journal of Engineering for Industry. 1987. vol. 109, pp. 49-57. 